\title{
GOMOS data characterisation and error estimation
}

\author{
J. Tamminen ${ }^{1}$, E. Kyrölä ${ }^{1}$, V. F. Sofieva ${ }^{1}$, M. Laine ${ }^{1}$, J.-L. Bertaux ${ }^{2}$, A. Hauchecorne ${ }^{2}$, F. Dalaudier ${ }^{2}$, D. Fussen ${ }^{3}$, \\ F. Vanhellemont ${ }^{3}$, O. Fanton-d'Andon ${ }^{4}$, G. Barrot ${ }^{4}$, A. Mangin ${ }^{4}$, M. Guirlet ${ }^{4}$, L. Blanot ${ }^{4}$, T. Fehr ${ }^{5}$, \\ L. Saavedra de Miguel $^{5}$, and R. Fraisse ${ }^{6}$ \\ ${ }^{1}$ Finnish Meteorological Institute, Earth Observation, Helsinki, Finland \\ ${ }^{2}$ LATMOS/IPSL, UVSQ, CNRS-INSU, Paris, France \\ ${ }^{3}$ BIRA-IASB, Brussels, Belgium \\ ${ }^{4}$ ACRI ST, Sophia Antipolis, France \\ ${ }^{5}$ ESA-ESRIN, Italy \\ ${ }^{6}$ EADS-Astrium, Toulouse, France
}

Received: 31 January 2010 - Published in Atmos. Chem. Phys. Discuss.: 11 March 2010

Revised: 7 September 2010 - Accepted: 23 September 2010 - Published: 8 October 2010

\begin{abstract}
The Global Ozone Monitoring by Occultation of Stars (GOMOS) instrument uses stellar occultation technique for monitoring ozone, other trace gases and aerosols in the stratosphere and mesosphere. The self-calibrating measurement principle of GOMOS together with a relatively simple data retrieval where only minimal use of a priori data is required provides excellent possibilities for long-term monitoring of atmospheric composition.

GOMOS uses about 180 of the brightest stars as its light source. Depending on the individual spectral characteristics of the stars, the signal-to-noise ratio of GOMOS varies from star to star, resulting also in varying accuracy of retrieved profiles. We present here an overview of the GOMOS data characterisation and error estimation, including modeling errors, for $\mathrm{O}_{3}, \mathrm{NO}_{2}, \mathrm{NO}_{3}$ and aerosol profiles. The retrieval error (precision) of night-time measurements in the stratosphere is typically $0.5-4 \%$ for ozone, about $10-20 \%$ for $\mathrm{NO}_{2}, 20-40 \%$ for $\mathrm{NO}_{3}$ and $2-50 \%$ for aerosols. Mesospheric $\mathrm{O}_{3}$, up to $100 \mathrm{~km}$, can be measured with $2-10 \%$ precision. The main sources of the modeling error are incompletely corrected scintillation, inaccurate aerosol modeling, uncertainties in cross sections of trace gases and in atmospheric temperature. The sampling resolution of GOMOS varies depending on the measurement geometry. In the data inversion a Tikhonov-type regularization with predefined target resolution requirement is applied leading to 2$3 \mathrm{~km}$ vertical resolution for ozone and $4 \mathrm{~km}$ resolution for other trace gases and aerosols.
\end{abstract}

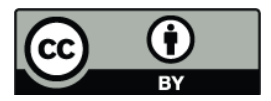

Correspondence to: J. Tamminen (johanna.tamminen@fmi.fi)

\section{Introduction}

Vertical profiles of stratospheric constituents have been measured using satellite instruments since 1979 when SAGE I (Stratospheric Aerosol and Gas Experiment I), the first instrument of the successful SAGE family, started its measurements. The solar occultation technique used by the SAGE instruments has turned out to be a reliable way of studying the atmospheric composition. Several instruments, in addition to the SAGE series, have utilised the same technique at various wavelength regions including ATMOS, SAM II, HALOE, POAM series, ACE-mission and SCIAMACHY. The success story of the solar occultation technique still continues and the recently launched solar occultation instrument SOFIE (Solar occultation for Ice Experiment) on board AIM satellite is targeted for studying the mesospheric composition.

In addition to the Sun, stars can also be used as light sources when studying the composition of the atmosphere. This was theoretically demonstrated by Hays and Roble (1968) and later also shown to work in practice. In 1996 US launched the MSX satellite with the UVISI instrument, which performed several stellar occultation measurements and demonstrated the potential of the technique to study globally the atmospheric composition and temperature (Yee et al., 2002; Vervack et al., 2003). For a more comprehensive summary of the occultation instruments see Bertaux et al. (2010).

The first instrument specifically developed for studying the composition of the atmosphere by using the stellar occultation technique is European Space Agency's GOMOS (Global Ozone Monitoring by Occultation of Stars) instrument on-board the Envisat satellite, launched in 1 March 2002 (Bertaux et al., 2004; Kyrölä et al., 2004; Bertaux et al.,

Published by Copernicus Publications on behalf of the European Geosciences Union. 


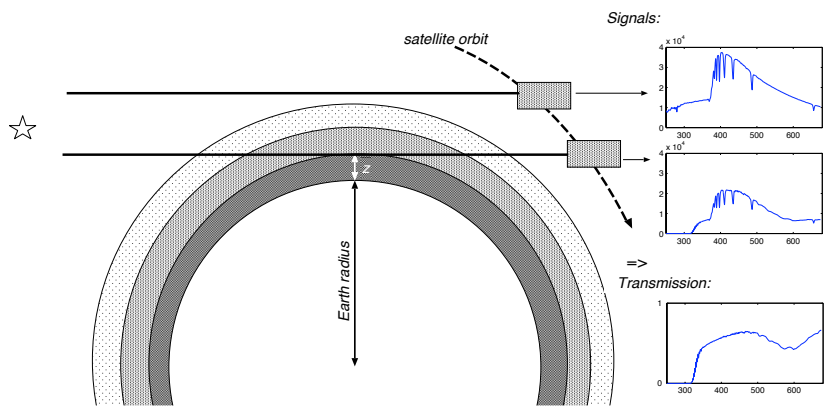

Fig. 1. The stellar occultation measurement principle of GOMOS. The horizontal transmission of the atmosphere is obtained by dividing the attenuated stellar spectrum with the reference spectrum measured above the atmosphere.

2010). GOMOS is an ultraviolet-visible spectrometer that covers wavelengths from $250 \mathrm{~nm}$ to $675 \mathrm{~nm}$ with $1.2 \mathrm{~nm}$ resolution. It has also two infrared channels at $756-773 \mathrm{~nm}$ and $926-952 \mathrm{~nm}$ with $0.2 \mathrm{~nm}$ resolution. Two photometers that are located at blue $(473-527 \mathrm{~nm})$ and red $(646-698 \mathrm{~nm})$ measure the stellar flux through the atmosphere at a sampling frequency of $1 \mathrm{kHz}$. By August 2009 GOMOS had observed about 668000 stellar occultations. An overview of the GOMOS instrument and highlights of the measurements are given in Bertaux et al. (2010)

The stellar occultation technique shares the main advantages of the solar occultation technique that include the selfcalibrated measurement principle (see Fig. 1), relatively simple inverse problem, and high vertical resolution. In addition, the stellar occultation technique benefits from the multitude of the stars to obtain a good global and temporal coverage. Compared to the Sun, stars are point-like sources, and thus provide an excellent pointing information. The disadvantage compared to the solar occultation is the low signal-to-noise ratio.

GOMOS is following about 180 different stars while they are descending behind the Earth limb. Since the stars differ both in brightness (magnitude) and in the spectrum of the light (originating from stellar properties and surface temperature) also data characteristics measured by GOMOS vary strongly. The signal-to-noise ratio varies significantly from star to star. In this respect, one might even consider GOMOS being a remote sensing mission that consists of 180 different instruments each having its own data characteristics.

The importance of the data characterisation and the error estimation is nowadays widely recognized (see e.g., Rodgers, 2000). The further utilisation of the remote sensing data, e.g., in the assimilation or in constructing time series, depends crucially on a proper error characterisation. The purpose of this paper is to characterise the quality of the GOMOS nighttime measurements. Both systematic errors and random errors are considered. The results shown here are based on estimating the impact of various assumptions that are made in the GOMOS data processing. The GOMOS Level $1 \mathrm{~b}$ and Level 2 data processing are described in detail in Kyrölä et al. (2010). A review of the geophysical validation of GOMOS data products is included in Bertaux et al. (2010).

In this paper, we characterise $\mathrm{O}_{3}, \mathrm{NO}_{2}, \mathrm{NO}_{3}$ and aerosol profiles that are retrieved from GOMOS UV-VIS spectrometer data at the altitude range $10-100 \mathrm{~km}$ during the nighttime. Only dark limb (night) occultations, i.e., occultations with solar zenith angle larger than $107 \mathrm{deg}$, are considered. The bright limb occultations (i.e., made during day time) are not considered here since the data quality in these measurements is much poorer due to the strong contribution from scattered solar light. The error characterisation, which we describe here, corresponds to official GOMOS processor IPF Version 6 data that will be available in spring 2011. Most of the results are also valid for IPF Version 5 data which is presently available. In addition, we have tried to indicate, when necessary, the difference in IPF Version 5 and 6 data. General features of GOMOS measurements are given in Sect. 2. The propagation of the random measurement error through the retrieval steps is discussed in Sect. 3. The contribution of various modelling errors are discussed in Sect. 4. The vertical resolution is discussed in Sect. 5. In Sect. 6 we give examples of the GOMOS error estimates and discuss the valid altitude range of the profiles. Finally, we summarize the most important sources of random and systematic errors in Sect. 7.

\section{GOMOS spectral measurements and their characteristics}

\subsection{Signal-to-noise ratio}

GOMOS measures stellar light through the atmosphere as the stars set behind the Earth limb. However, stars are not similar and this has an impact on GOMOS results as well. The most significant characteristic is that the accuracy of the retrieved parameters depends strongly on stellar properties. The measured stellar signals and further the transmission spectra, which are used as the data in the GOMOS retrievals, vary strongly with the stellar brightness and temperature. This is illustrated in Fig. 2, where examples of the GOMOS transmission spectra at different altitudes $(10-70 \mathrm{~km})$ are shown for different stars (bright and cool, bright and hot, dim and cool and dim and hot). We observe clearly that the transmission spectra of dim stars are much noisier compared to bright stars. In addition, the stellar temperature has an impact: hot stars have the maximum intensity of the radiation at UV wavelengths whereas cool stars have the maximum at the VIS wavelengths and the UV part is very noisy.

In Fig. 3 the GOMOS signal-to-noise ratio (SNR, defined as transmission divided by estimated noise) at 3 different wavelength regions (UV and 2 visible) are shown in three cases: Sirius (the brightest star, star number 1 in the GOMOS 

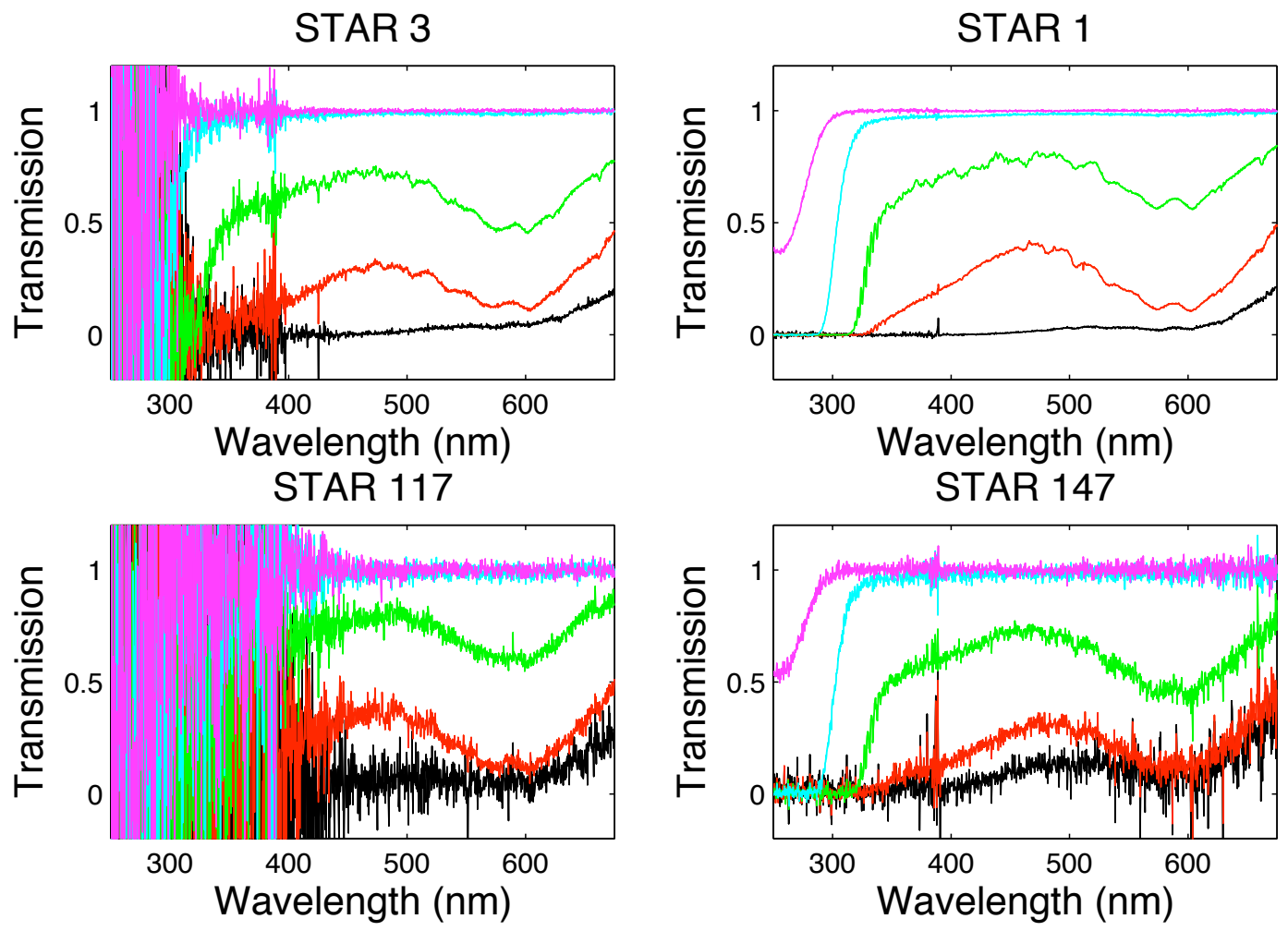

Fig. 2. Examples of GOMOS transmissions (corrected for refractive effects) measured using different stars. Top row on left: bright and cool star $\left(M_{\mathrm{V}}=-0.05, T=4300 \mathrm{~K}\right)$, on right: bright and hot star $\left(M_{\mathrm{V}}=-1.44, T=11000 \mathrm{~K}\right)$. Bottom row, on left: dim and cool star $\left(M_{\mathrm{V}}=2.7\right.$, $T=3800 \mathrm{~K})$, on right: $\operatorname{dim}$ and hot $\operatorname{star}\left(M_{\mathrm{V}}=2.88, T=26000 \mathrm{~K}\right)$. Five lines correspond to altitudes $10 \mathrm{~km}(\mathrm{black}), 20 \mathrm{~km}(\mathrm{red}), 30 \mathrm{~km}$ (green), $50 \mathrm{~km}$ (cyan) and $70 \mathrm{~km}$ (magenta).

star catalogue with magnitude $M_{\mathrm{v}}=-1.44$ and temperature $T=11000 \mathrm{~K}$ ), a bright and a cool star (star number $4, M_{\mathrm{V}}=$ $-0.01, T=5800 \mathrm{~K}$ ) and a dim and a cool star (star number $\left.117, M_{\mathrm{v}}=2.7, T=3800 \mathrm{~K}\right)$. In the retrieval it is important to have a sufficient SNR in spectral regions where constituents absorb or scatter light. These regions depend on constituent. For retrieving ozone at high altitudes, above $40 \mathrm{~km}$, the Hartley band $(248-310 \mathrm{~nm})$ is crucial and at this altitude region the hot stars provide significantly better results than the cool stars. The average SNR of GOMOS at UV around $50 \mathrm{~km}$ using Sirius is $130-160$ whereas using cool stars $(T<6000 \mathrm{~K}$, stars 4 and 117 in Fig. 3) the SNR is close to zero. At lower altitudes, where the retrieval is most sensitive to Chappuis band at visible wavelengths, both hot and cool stars provide similar SNR. For $\mathrm{NO}_{3}$ the situation is quite the opposite. The strongest $\mathrm{NO}_{3}$ signal comes from visible wavelengths around $660 \mathrm{~nm}$, hence the cool stars are slightly more favourable for $\mathrm{NO}_{3}$ retrieval. Aerosols and $\mathrm{NO}_{2}$ are retrieved mainly below $50 \mathrm{~km}$ using a wide spectral window and therefore the retrievals do not have significant dependence on the stellar temperature.

Statistics of the stellar characteristics in the night-time occultations during years 2002-2008 are given in Table 1. The occultations are divided into nine categories depending the stellar brightness and temperature. Roughly two thirds of the occultations are performed using either hot or medium temperature stars and about half using either bright or medium brightness stars.

\subsection{Spatio-temporal distribution of GOMOS measurements}

\subsubsection{Mission planning}

GOMOS uses about 180 of the brightest stars with stellar magnitude brighter than $3\left(M_{\mathrm{V}}<3\right)$ as the light source. Since there are often several stars available simultaneously in the GOMOS field-of-view, some prioritisation needs to be made. The purpose of the GOMOS mission planning is to select for each orbit the optimal set of 25-40 stars that will be used for occultation measurements. About half of the occultations are made in the night-time. The optimisation is done using several criteria, like the geographical coverage, stellar brightness and temperature, see Kyrölä and Tamminen (1999) for more details about selecting the stars.

The selected set of stars is repeated for several orbits until the stars are out of the field-of-view. Occultations of the same star at successive orbits are made at the same latitude 


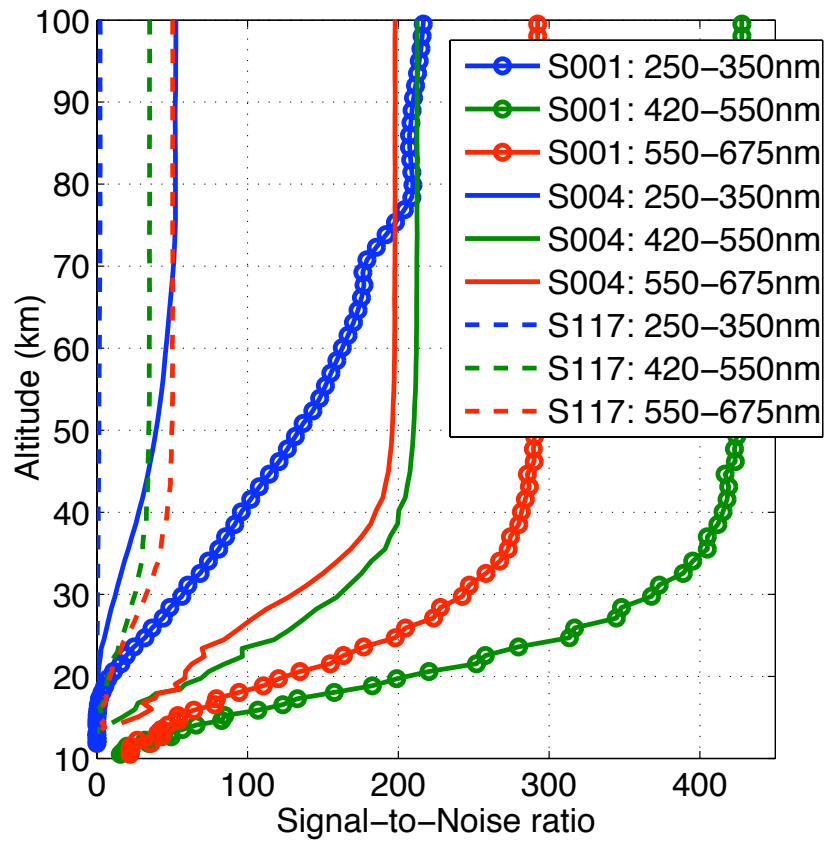

Fig. 3. The average signal-to-noise ratio for three stars as a function of altitude in 2003. Star 1 , bright $\left(M_{\mathrm{V}}=-1.44\right)$ and hot star ( $T=11000 \mathrm{~K}$, solid line with circles) Star 4 , bright and cool star ( $M_{\mathrm{V}}=-0.01, T=5800 \mathrm{~K}$, solid line) and star 117, dim and cool star $\left(M_{\mathrm{V}}=2.7, T=3800 \mathrm{~K}\right.$, dashed line). Blue lines correspond to averaged SNR at UV: $250-350 \mathrm{~nm}$, red line averaged SNR at VIS: $420-550 \mathrm{~nm}$ and green line averaged SNR at VIS: $550-675 \mathrm{~nm}$.

Table 1. Occultation statistics during time period 2002-2008 divided by different stellar classes depending on brightness and approximated surface temperature.

\begin{tabular}{rcccc}
\hline & Bright & Medium & Dim & Tot \\
& $M_{\mathrm{v}}<0.8$ & $M_{\mathrm{v}}: 0.8-2$ & $M_{\mathrm{V}}>2$ & \\
\hline Cool, $T \leq 6000 \mathrm{~K}$ & $3 \%$ & $7 \%$ & $22 \%$ & $32 \%$ \\
$T: 6000-10000 \mathrm{~K}$ & $5 \%$ & $4 \%$ & $11 \%$ & $19 \%$ \\
Hot, $T \geq 10000 \mathrm{~K}$ & $11 \%$ & $20 \%$ & $18 \%$ & $49 \%$ \\
\hline Tot & $18 \%$ & $31 \%$ & $51 \%$ & $100 \%$ \\
\hline
\end{tabular}

band but with varying longitude (about 14/day). In Fig. 4 the latitude coverage of the night-time occultations during 2003 are shown. The individual stars can typically be followed for several months in a row.

\subsubsection{Geographical distribution of GOMOS measurements}

The GOMOS measurements cover the whole globe from pole to pole. This can be seen in Fig. 5 where the geographical distribution of the GOMOS night-time measurements from summer 2002 to autumn 2009 are shown. We see that quite a good global coverage can be obtained using 10 deg latitude

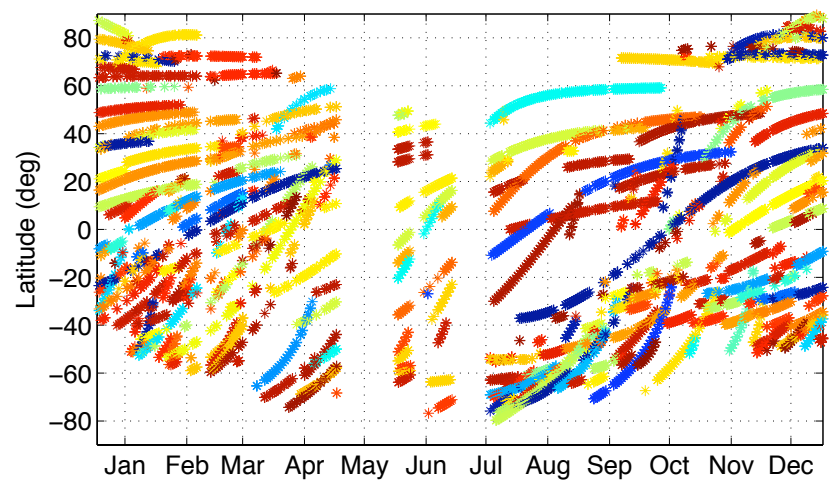

Fig. 4. Latitude coverage of GOMOS night measurements in 2003. The colours indicate the stellar brightness in magnitude. Dark blue indicates bright stars and red dim stars.

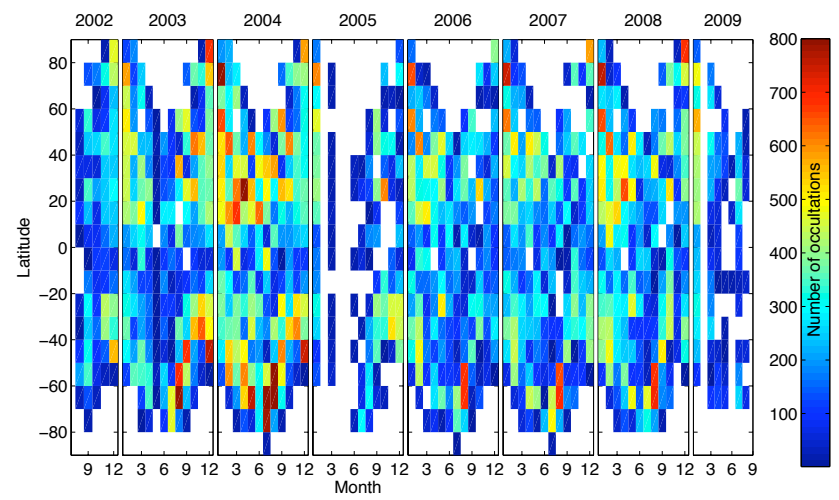

Fig. 5. Latitudinal distribution of GOMOS data availability during summer 2002-autumn 2009. Only night-time data is considered here, i.e., solar zenith angle larger than $107 \mathrm{deg}$. Colour coding refers to number of available night-time occultations.

bands. In particular, the unique measurements of GOMOS during polar night have been used extensively e.g., in studies of long term effects of solar proton events during polar night (Seppälä et al., 2007; Verronen et al., 2005) and in studying the effect of intense warming and air descent (Hauchecorne et al., 2007).

Depending on the season, there is some variation in the distribution of the measurements as the stars are not distributed evenly in the sky (see Fig. 5). In addition, the nighttime measurements do not cover the summer poles. The calibration measurements that are performed at each orbit close to the equator cause some reduction in the number of occultations there.

The yearly variations in the measurement distribution are caused by technical problems in the instrument. In May 2003 there was a technical anomaly and the number of measurements was low during May and June in 2003. After another technical anomaly in January 2005 the viewing angle was slightly reduced and the number of (night-time) profiles went 


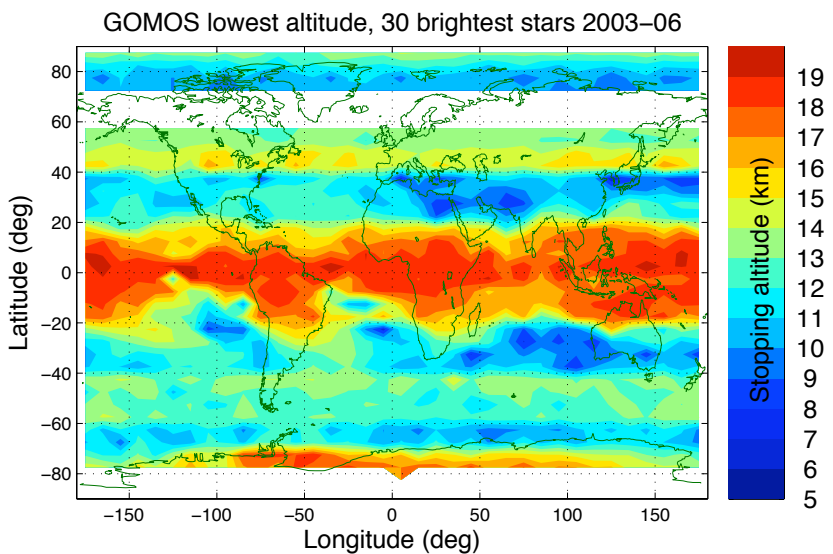

Fig. 6. Distribution of the mean occultation stopping altitude of 30 brightest stars in 2003-2006.

down from about 200 to 150 profiles per day. In 2009 the number of occultations has been clearly less than in the previous years and this is again due to a technical anomaly that caused the occultations to stop already at high altitudes. In December 2009 the situation improved and since then the performance has been almost normal (not shown in figure).

In principle, GOMOS measures each year the same stars at the same latitude regions which is very useful when making a time series analysis based on the data. Some changes have, however, taken place during the mission due to the reduced viewing angle. Moreover, it is important to keep in mind that there are differences in the overall global coverage and some latitude bands are covered more densely than the others.

\subsubsection{Altitude range}

The GOMOS instrument is equipped with a star tracker operating at $625-950 \mathrm{~nm}$, which follows the star by keeping the image of the star in the centre of the slit. The technique has worked reliably (except the last technical anomaly in 2009) and the stars can typically be tracked from the top of the atmosphere (120-150 km) down to 5-20 km tangent altitude. It seems that when no clouds are present, stars can be followed as low as $5 \mathrm{~km}$ altitude (especially bright stars). The presence of clouds in the field-of-view leads to loosing the signal. Other factors affecting the lowest altitude are stellar brightness (the brighter the star, the lower the tangent altitude) and refraction (the star image can fall outside the field-of-view due to refraction). Figure 6 shows the lowest measurement altitude for 30 of the brightest stars $\left(M_{v}<1.6\right)$. This distribution is in good general agreement with the maps of the cloud top height (e.g., http://isccp.giss.nasa.gov/index.html), thus indicating that the main reason for terminating the occultations of bright stars is the presence of clouds. In tropics, the lowest altitude is $15-18 \mathrm{~km}$ because of frequent presence of high clouds (cirrus and convective clouds). Above the South Pole the measurements are also often terminated at $15-18 \mathrm{~km}$, most probably because of frequent occurrence of polar stratospheric clouds (note that polar regions are not covered by GOMOS in summer). The lowest altitude in occultations of bright stars can potentially provide valuable information about cloud top height.

\section{Error propagation through GOMOS retrieval}

The random error plays an important role in the GOMOS total error budget, unlike several other remote sensing instruments which are dominated by systematic errors. The random errors in GOMOS data are mainly due to the propagation of measurement noise and imperfect scintillation correction. First we discuss how the measurement noise is propagated through the GOMOS retrieval steps. The GOMOS retrieval procedure is described in detail in Kyrölä et al. (2010) and we will use here the same notation as much as possible.

The GOMOS data retrieval is based on describing the measurement and the quantities to be retrieved as random variables. By error propagation we mean how the measurement noise and possible modelling errors impact the uncertainty of the retrieved quantities. A natural framework for studying the uncertainties is obtained by describing the solution as Bayesian a posteriori distribution. In the operational GOMOS retrieval processor maximum likelihood estimation is used. The posterior uncertainties are approximated with Gaussian distribution whose mean and covariance are computed. The covariance matrix describes the uncertainty of the retrieved quantities.

\subsection{Error propagation through the spectral inversion}

The GOMOS retrieval problem is solved in two steps which are called spectral inversion and vertical inversion. In spectral inversion horizontally integrated column densities of gases and aerosol parameters (denoted with vector $N$ ) are simultaneously fitted to the observed transmission data due to extinction $T_{\mathrm{ext}}^{\mathrm{obs}}$. Measurements at successive tangent altitudes are treated separately. No prior information of the constituents is used in the retrieval. Assuming that the noise in the transmission is Gaussian, the problem of finding the maximum likelihood point is equal with finding the solution that minimizes the sum of squared residuals term:

$\mathrm{S}(\mathrm{N})=\left(T_{\mathrm{ext}}(N)-T_{\mathrm{ext}}^{\mathrm{obs}}(N)\right) C^{-1}\left(T_{\mathrm{ext}}(N)-T_{\mathrm{ext}}^{\mathrm{obs}}(N)\right)^{T}$

(see Eq. (42) in Kyrölä et al. (2010)). (Note, that this equals formally maximum a posteriori estimate with noninformative prior). Here $T_{\mathrm{ext}}$ refers to the modelled transmission due to extinction

$T_{\text {ext }}=e^{-\tau}=e^{-\sum_{j} \sigma_{j} N_{j}-\tau_{\text {aerosols }}}$

where $\sigma$ denotes the absorption cross sections of gases. The spectral dependence of the aerosols is modelled using second order polynomial

$\tau_{\text {aerosols }}=c_{0}+c_{1}\left(\lambda-\lambda_{\text {ref }}\right)+c_{2}\left(\lambda-\lambda_{\text {ref }}\right)^{2}$ 
where $\lambda$ denotes the wavalength and the reference wavelength $\lambda_{\text {ref }}=500 \mathrm{~nm}$. The three aerosol parameters $\left(c_{0}, c_{1}, c_{2}\right)$ are estimated together with the horizontally integated densities of $\mathrm{O}_{3}, \mathrm{NO}_{2}$ and $\mathrm{NO}_{3}$ so that we have all together six parameters to be estimated: $N=$ $\left[N_{\mathrm{O}_{3}}, N_{\mathrm{NO}_{2}}, N_{\mathrm{NO}_{3}}, c_{0}, c_{1}, c_{2}\right]$. For more details of the retrieval see Kyrölä et al. (2010).

The covariance matrix $C$ in Eq.(1) includes both measurement and modelling errors. In the present GOMOS processing (IPF Version 5) the modelling error is ignored, but in the updated version (IPF Version 6) this is also taken into account (see Sect. 4.1).

The inverse problem is non-linear and it is solved iteratively by applying Levenberg-Marquardt algorithm (Press et al., 1992). The algorithm assumes that the posterior distribution is roughly Gaussian close to the point that minimizes the sum of squared residuals, so that the uncertainty of the horizontal column densities can be characterised with the estimate and the covariance matrix $C_{N}$. The LevenbergMarquardt algorithm returnes also this covariance matrix whose diagonal elements characterise the variance of the error estimates of the horizontal column densities.

The validity of the assumption of Gaussian posterior distribution can be studied by applying Monte Carlo sampling methods to estimate the real posterior distribution without this assumption. The Markov chain Monte Carlo (MCMC) technique has been successfully applied to the GOMOS spectral inversion (Tamminen and Kyrölä, 2001; Tamminen, 2004). It has been shown that Gaussian posterior distribution is a good approximation in the GOMOS spectral inversion (Tamminen, 2004).

\subsubsection{Correlated errors after the spectral inversion}

As mentioned above, in the spectral inversion $\mathrm{O}_{3}, \mathrm{NO}_{2}, \mathrm{NO}_{3}$ and aerosol parameters are retrieved simulatenously. Since their cross sections overlap spectrally, some correlation in the retrieval errors are observed. The amount of correlation changes depending on the altitude due to the changing effective spectral region. The off-diagonal values of the posterior covariance matrix $C_{N}$ describe the correlations in the errors. In Fig. 7 we give an example of the correlation coefficients $\left.\left(R_{N}(i, j)=C_{N}(i, j) / \sqrt{(} C_{N}(i, i) C_{N}(j, j)\right)\right)$ between the errors in $\mathrm{O}_{3}$ and the other retrieved parameters $\left(\mathrm{NO}_{2}, \mathrm{NO}_{3}\right.$, and three aerosol parameters) after the spectral inversion. In the figure, the correlation coefficients are plotted for all retrieval altitudes. We note that, in this case, the error estimates of the horizontally integrated column $\mathrm{O}_{3}$ are mainly correlated with the aerosol errors and this has largest effect below about $25 \mathrm{~km}$. Some positive correlation with $\mathrm{O}_{3}$ and $\mathrm{NO}_{2}$ column errors can also be seen, but that is generally below 0.4 . The maximum correlation $(\sim 0.5)$ seems to be around $20-40 \mathrm{~km}$ depending on the stellar type and the atmospheric composition. The correlation between $\mathrm{O}_{3}$ and $\mathrm{NO}_{3}$ is negligible. The correlation structure varies somewhat depending on the stel-

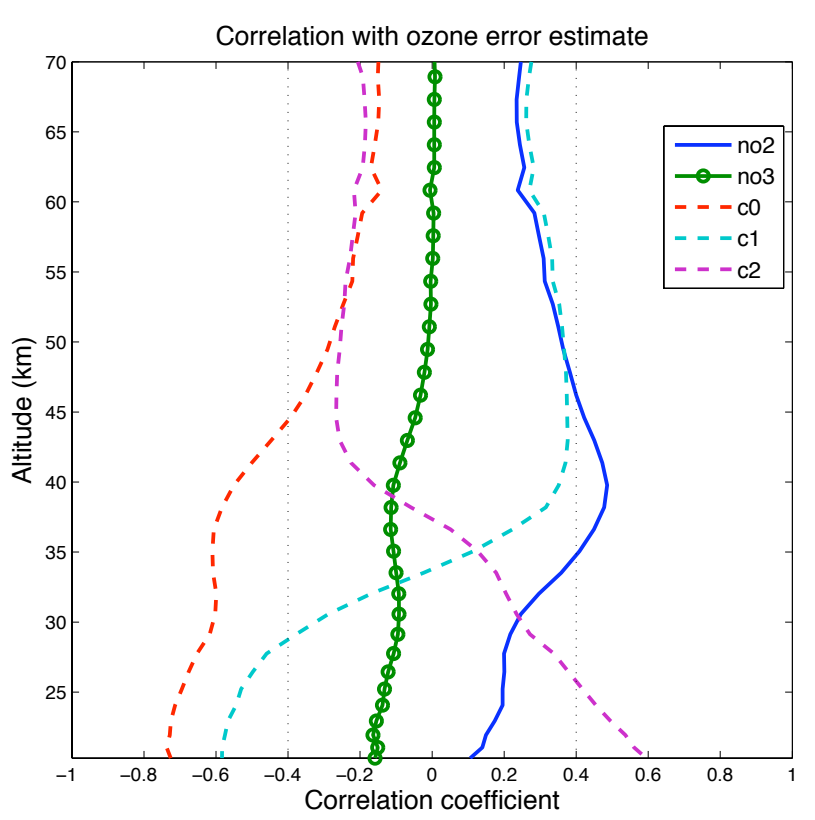

Fig. 7. Examples of correlation coefficients between the error estimates of horizontally integrated $\mathrm{O}_{3}$ and $\mathrm{NO}_{2}$ (solid blue line), $\mathrm{NO}_{3}$ (green circles) and three aerosol parameters (dashed lines). Star 29 in tropics.

lar characteristics (the example given in Fig. 7 corresponds to a hot star).

In principle, the correlation in errors should be taken into account when analysing, e.g., the correlations of gases. However, this is typically not done, and in GOMOS case this information is not available for profiles but only for horizontally integrated column densities after the spectral inversion. A simplified simulation study was performed in order to get an idea how much the correlated errors impact if we want to estimate the correlation of the gases (e.g., $\mathrm{O}_{3}$ and $\mathrm{NO}_{2}$ ). The study showed that the estimated correlation of the gases was only very slightly biased when the correlation in their errors was not taken into account. However, the accuracy of the estimated correlation of the gases was more influenced. Based on this exercise we can conclude that when using GOMOS data to study correlation between $\mathrm{O}_{3}$ and $\mathrm{NO}_{2}$ or aerosols the significance of the correlation may be either overestimated or underestimated. If the correlation we found is negative/positive and the errors are also correlated negatively/positively then the significance of the correlation is underestimated and if the errors are correlated differently, positively/negatively, then the significance of the correlation is overestimated.

\subsubsection{Random error propagation through vertical inversion}

In the vertical inversion the horizontally integrated column densities are transformed to local densities using information 


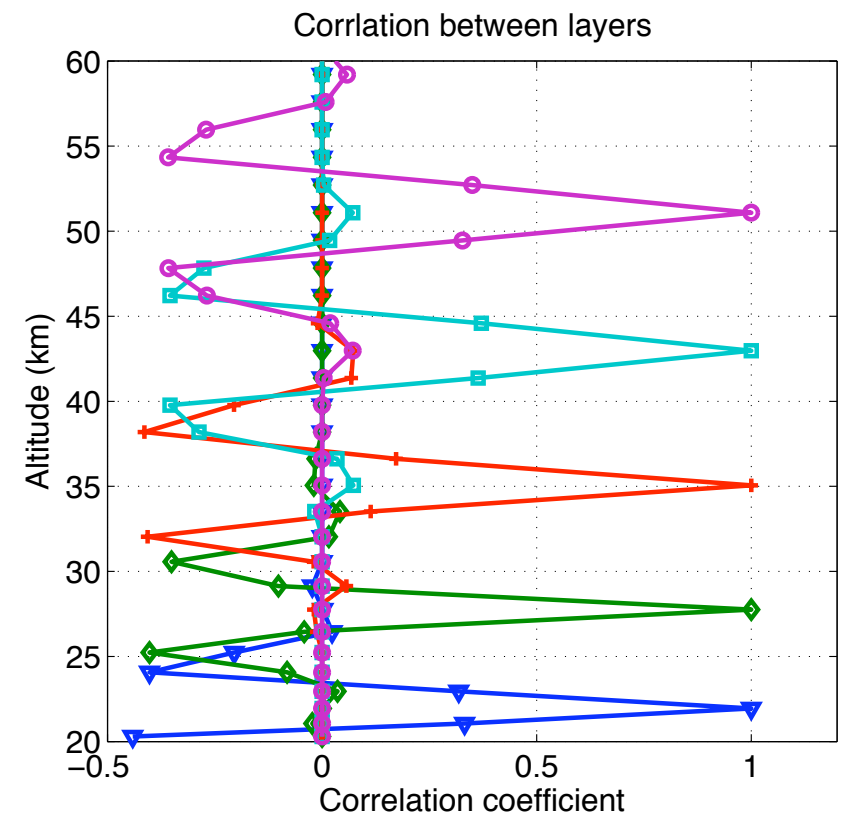

Fig. 8. Correlation of the retrieval error with neighbouring layers. Five selected altitudes $(23 \mathrm{~km}, 28 \mathrm{~km}, 35 \mathrm{~km}, 44 \mathrm{~km}$ and $51 \mathrm{~km})$ are shown in different colours. Each of the lines correspond to correlations with the selected retrieved altitude (for which the correlation coefficient equals 1) and the errors layers above and below it.

about the ray path of the measurement. Each constituent is treated separately and the correlations between the errors of the horizontal column densities are not taken into account, see Kyrölä et al. (2010) for description.

The vertical inversion is linear so the error propagation can be directly estimated. Let us assume that $C_{N}$ denotes the estimated error covariance of horizontal column density profile of one constituent after the spectral inversion $\left(C_{N}\right.$ is a diagonal matrix). Now the covariance matrix of the retrieved profile is simply

$C_{\rho}=L C_{N} L^{T}$,

where $L$ is the retrieval matrix so that $\rho=L N$ (corresponding to Eq. (49) in Kyrölä et al. (2010)). The diagonal elements of of the posterior covariance matrix $C_{\rho}$ describe the variance of the estimated local density values whereas the off-diagonal elements of the covariance matrix $C_{\rho}$ characterise the correlation between the retrieved densities at successive layers. In GOMOS data products six most significant off-diagonal elements are reported. After applying the Tikhonov regularization the errors of the nearby layers are somewhat correlated, see Fig. 8 where the correlation coefficients for the ozone retrieval $\left(R_{\rho}(i, j)=\right.$ $\left.\left.C_{\rho}(i, j) / \sqrt{(} C_{\rho}(i, i) C_{\rho}(j, j)\right)\right)$ are plotted for five selected altitudes. We see that above $35 \mathrm{~km}$, where the Tikhonov regularization is stronger, also the correlation in the errors is larger, and involves about 3 layers above and below the retrieval height. Below $30 \mathrm{~km}$ only errors from 2 layers be- low and above the retrieval altitude are slightly correlated. In oblique occultations the adjacent layers are correlated more because the regularization is stronger than in the vertical occultations.

\section{Modelling errors}

In the GOMOS retrieval, the faint signal is compensated by using a wide range of spectral pixels for the data processing. The advantage is clear - we maximize the use of the data, but, as a drawback, the consistency in the modelling of the wide wavelength band becomes much more important. In the GOMOS spectral inversion residuals (i.e., measured transmission spectra minus modelled ones) we see some structures which are mainly due to imperfect scintillation correction. They are considered as the largest modelling error in the GOMOS retrieval in the stratosphere. The imperfect modelling of the aerosol contribution is an important source of modelling error especially at low altitudes. Other sources of modelling error are uncertainties in the absorption cross sections and temperature. Relatively negligible impact is seen due to uncertainty of neutral density profile, ray path computation and potentially missing constituents.

\subsection{Scintillation - dilution correction}

When the stellar light traverses through the atmosphere, it is affected also by the refractive effects, dilution and scintillation, which need to be taken into account in the retrieval. The approach taken in the GOMOS data processing is to remove these effects before performing the inversion (see Kyrölä et al., 2010 for a general description of the algorithms).

The dilution term is approximated using ECMWF air density. As the refraction can be accurately computed, the error caused by this assumption is negligible in the retrieved profiles (Sofieva et al., 2006).

In the GOMOS retrievals, the perturbations in the stellar flux caused by scintillations are corrected by using additional scintillation measurements by the fast photometer operating in low-absorption wavelength region (Dalaudier et al., 2001; Sofieva et al., 2009). The quality of the scintillation correction and its limitations are discussed in Sofieva et al. (2009) where it was shown that the applied scintillation correction removes significant part of the perturbations in the recorded stellar flux, but it is not able to remove scintillations generated by the isotropic turbulence. The remaining perturbations, due to the incomplete scintillation correction, are not negligible: in oblique occultations of bright stars, they can be comparable or even exceed the instrumental noise by a factor of 2-3 at the altitude $20-45 \mathrm{~km}$ (Sofieva et al., 2009) (Fig. 9). This causes about $0.5-1.5 \%$ additional error in the ozone retrievals at the altitude range of $20-45 \mathrm{~km}$ (Sofieva et al., 2009). 

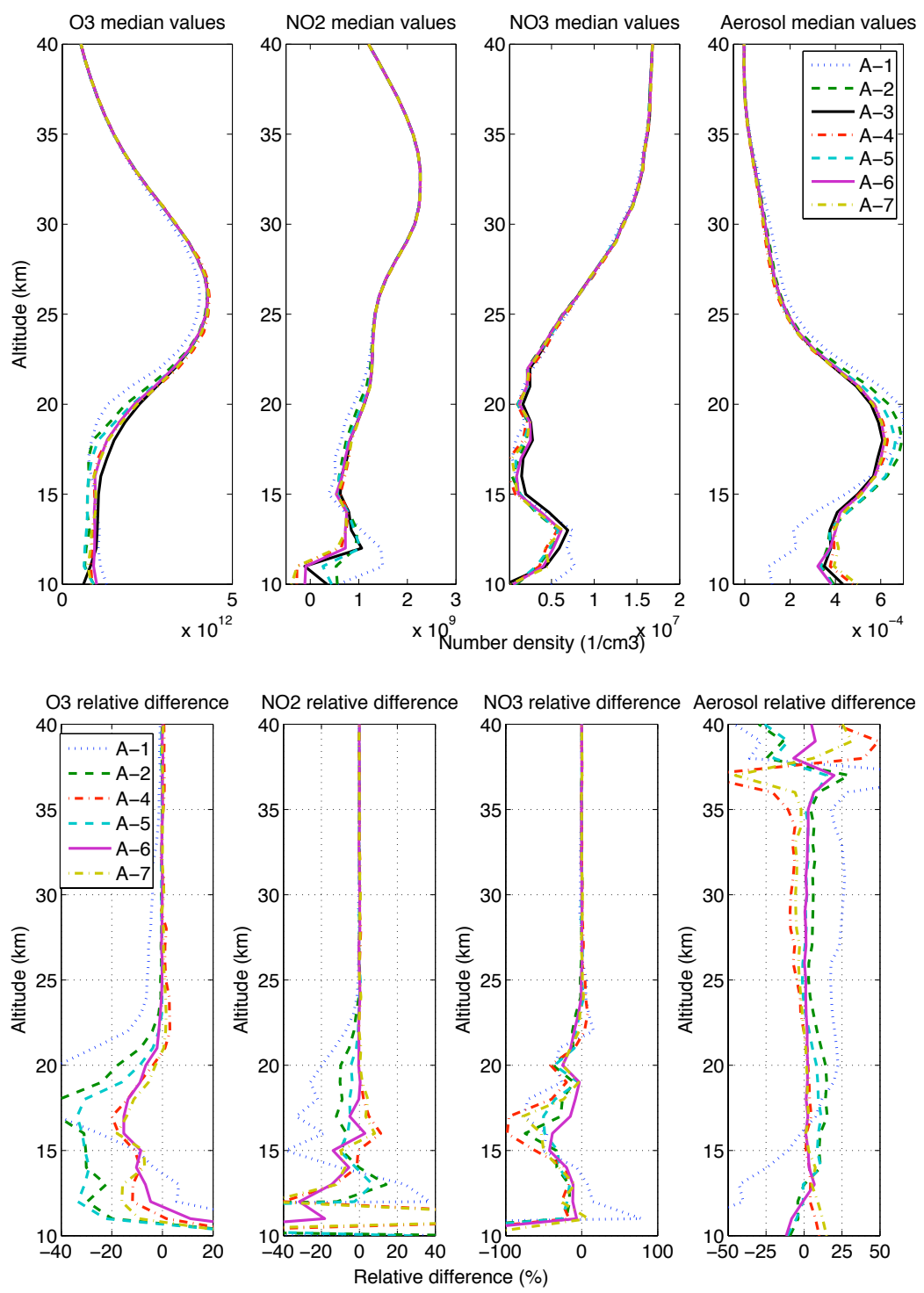

Fig. 9. Sensitivity of $\mathrm{O}_{3}, \mathrm{NO}_{2}, \mathrm{NO}_{3}$ and aerosol extinction (at $500 \mathrm{~nm}$ ) on selection of aerosol model. Seven aerosol models are compared (denoted with different line types and colours. Top row: median profiles and bottom row relative difference compared to second order polynomial model which is used in the operational GOMOS processing. From left: $\mathrm{O}_{3}, \mathrm{NO}_{2}, \mathrm{NO}_{3}$ and aerosol extinction at $500 \mathrm{~nm}$. See text for the different aerosol models included.

The modelling error from the imperfect scintillation correction can be taken into account in the spectral inversion by introducing a wavelength correlated modelling error. The parametrisation of the scintillation correction errors is presented in Sofieva et al. (2010). In the proposed parametrization, which is based on statistical analyses of GOMOS residuals and the theory of isotropic scintillations, the scintillation correction error is assumed to be a Gaussian random variable with zero mean and a non-diagonal covariance matrix (Sofieva et al., 2010). When the scintillation correction errors are taken into account, the normalized $\chi 2$ values which reflect the agreement between the measurement and modelling become close to the optimal value 1 . This improvement ensures that the estimated accuracy of the retrieved profiles is closer to the reality after including the modelling error com- ponent to the retrieval. In the present operational GOMOS Level 2 algorithm (IPF Version 5) this is not included, but it will be implemented in the new IPF Version 6 in spring 2011.

The incomplete scintillation correction is the main source of GOMOS modelling errors in the stratosphere (at altitudes $20-45 \mathrm{~km}$ ). However, this modelling error is not systematic but random in nature. By averaging measurements on successive layers or requiring smoothness of the retrieved profile (as is done in GOMOS vertical inversion) the effect of this modelling error reduces.

\subsection{Uncertainty in aerosol modelling}

In the GOMOS spectral inversion absolute cross sections are used and the aerosols are also inverted simultaneously 

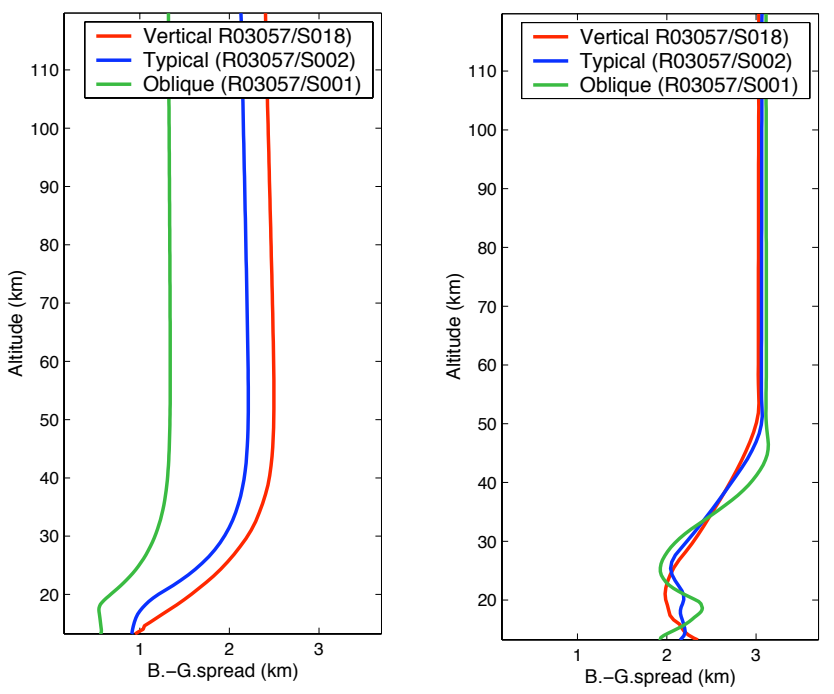

Fig. 10. Vertical resolution (Backus-Gilbert spread) of the ozone profiles in different occultation geometries as a function of altitude. On left: without regularizing, on right: with target resolution regularization. Red line denotes vertical occultation, blue line typical occultation and green line oblique occultation.

with the trace gases. The aerosol cross sections depend on the aerosol size distribution and composition, which are unknown. A practical approach is to use a simplified wavelength dependent model for the aerosol cross sections. In the present algorithm, aerosol cross sections are assumed to depend on the wavelength $(\lambda)$ according to a second order polynomial, see Eq. (3). Three parameters are fitted. In the present operational processor, the second order polynomial is used, but first or third order polynomials could also be considered.

A sensitivity study was made in order to quantify the modelling error caused by using this simplified aerosol model. This was done by comparing retrieval results using 7 different aerosol models, namely constant (A-1), first (A-2), second (A-3) and third order (A-4) polynomial in $\lambda$ and first (A-5), second (A-6) and third order polynomial (A-7) in $\frac{1}{\lambda}$. Aerosol model A-3 corresponds to the parametrization that is described in Eq. (3) and used in the operational GOMOS data processing IPF (both Versions 5 and 6). As a test case we used more than 1000 occultations and compared the median values in this set, see Fig. 9. These results are obtained using the presently available GOMOS Version 5 processing. We note that the (physically most unrealistic) model A-1 gives quite different results than the others. By comparing the effect of the other models we can conclude the following. The aerosol model selection has its largest effect at low altitudes below $20 \mathrm{~km}$. For $\mathrm{O}_{3}$, the sensitivity is of the order of $20 \%$ below $20 \mathrm{~km}$ and $1-5 \%$ between $20-25 \mathrm{~km}$. Above $25 \mathrm{~km}$ the uncertainty in the aerosol modelling does not effect much $\mathrm{O}_{3}$ retrieval. It is interesting to note that the aerosol model that is used in the GOMOS retrieval results in slightly larger $\mathrm{O}_{3}$ concentrations than the other models. For $\mathrm{NO}_{2}$, the sensitivity is typically around $10 \%$ between $15-20 \mathrm{~km}$. Above $20 \mathrm{~km}$ the effect is small, less than $5 \%$. For $\mathrm{NO}_{3}$, the uncertainty can be as large as $100 \%$ around $15-20 \mathrm{~km}$, but above $25 \mathrm{~km}$, which is the lowest reasonable altitude for $\mathrm{NO}_{3}$, it does not affect the results significantly. The effect in aerosol extinction is below $10 \%$ up to $35 \mathrm{~km}$ and larger above.

In a recent publication, a technique for selecting the best aerosol model in the GOMOS spectral inversion is developed using Markov chain Monte Carlo technique (Laine and Tamminen, 2008). It is shown that the model selection can be implemented simultaneously with the parameter estimation to the spectral inversion. More work is, however, needed to show the quantitative advantage of this method in practice.

\subsection{Uncertainty of cross sections and atmospheric temperature}

The retrieval of the atmospheric constituents from the GOMOS measurements is based on assuming a good knowledge of the cross sections of the retrieved gases $\mathrm{O}_{3}, \mathrm{NO}_{2}$ and $\mathrm{NO}_{3}$. See Kyrölä et al. (2010) for more details of the cross sections that are used in GOMOS retrievals. The errors in the cross sections are, unfortunately, not well known. Some studies, assuming independent Gaussian distributed uncertainty have been performed, but the validity of these estimates is, however, limited, since the uncertainty is not realistically modelled. By comparing several sets of laboratory measured $\mathrm{O}_{3}$ cross sections, it is obvious that these measurements include uncertainties both in the absolute values and in their temperature dependence, and the uncertainties are not independent (see e.g., Burrows et al., 1999). When the nature of the uncertainty is not known, it is also difficult to take into account in the inverse problem. By making a sensitivity study and using different sets of ozone cross sections in GOMOS spectral inversion we observe a difference of the order of $1-1.5 \%$ in the ozone retrieval.

The absorption cross sections of $\mathrm{O}_{3}, \mathrm{NO}_{2}$ and $\mathrm{NO}_{3}$ depend on the temperature and, therefore, some error is also caused by the uncertainty in the atmospheric temperature. A part of the systematic bias in the cross sections could be modelled as the uncertainty in the temperature. Unlike in several other instruments, in the operational GOMOS retrieval the atmospheric temperature is not fitted but assumed to be known. ECMWF temperature is used below $1 \mathrm{hPa}(\approx 50 \mathrm{~km})$ and MSIS90 temperature above. If a moderate Gaussian uncertainty (with zero mean and $2 \mathrm{~K}$ standard deviation) in the temperature information is taken into account, the error in $\mathrm{O}_{3}$ retrieval increases slightly $(<0.5 \%)$ at $30-60 \mathrm{~km}$ altitude range (Tamminen, 2004). At these altitudes the retrieval is based on the Huggins band where the cross sections are known to be strongly temperature dependent. The effect is less significant with $\mathrm{NO}_{2}$ and $\mathrm{NO}_{3}$ retrievals, which are more dominated by the random measurement noise. 
Further work is still needed to understand the nature of the uncertanties in the cross sections and to estimate properly the effect in the GOMOS products. This work will be continued as a part of the IGACO-O3/UV activity, initiated by IO3C (International Ozone Commision) and WMO-GAW, on the evaluation of the absoption cross sections of ozone (ACSO, see http://igaco-o3.fmi.fi/ACSO/). This activity, which involves several ground based and satellite instruments using the Huggins band, will be finalized by 2011.

\subsection{Uncertainty of neutral density profile}

In earlier versions of the GOMOS data processing also the neutral density was inverted simultaneously with $\mathrm{O}_{3}, \mathrm{NO}_{2}$, $\mathrm{NO}_{3}$ and aerosols. Due to the similar nature of Rayleigh scattering cross sections and aerosol scattering cross sections, the neutral density and aerosols are strongly correlated in retrievals. In order to improve the aerosol retrieval, it was decided to fix the the neutral density concentration to ECMWF analysis values below $50 \mathrm{~km}$ and to use MSIS90 model values above. Assuming that the uncertainty of ECMWF neutral density is around $2 \%$, we observe negligible $(<1 \%)$ effect in $\mathrm{O}_{3}, \mathrm{NO}_{2}$ and $\mathrm{NO}_{3}$ retrievals. However, the effect in aerosol retrieval is larger. Around $22-40 \mathrm{~km}$, the sensitivity is generally around 5-10\% (with maximum $15 \%$ around $27 \mathrm{~km}$ ). Below $22 \mathrm{~km}$, the effect is less significant being smaller than $5 \%$.

\subsubsection{Missing constituents}

The wavelength band $248-690 \mathrm{~nm}$ that is used for retrieval of $\mathrm{O}_{3}$, aerosols, $\mathrm{NO}_{2}$ and $\mathrm{NO}_{3}$ contains also absorption by $\mathrm{OClO}, \mathrm{BrO}$ and $\mathrm{Na}$. However, in individual retrievals their impact is so small that the error caused by not including them in the modelling is negligible. For example, only by averaging several hundreds of measurements the signatures of $\mathrm{Na}$ can be seen (Fussen et al., 2004). The wavelengths that include $\mathrm{O}_{2}$ signature at $627-630 \mathrm{~nm}$ are excluded from the inversion.

\subsection{Uncertainty in ray tracing and measurement position}

One of the advantages of the stellar occultation technique is that the measurement target is a point source whose position is well known. Therefore, the uncertainty in the ray path and its tangent altitude is only due to the uncertainty in the satellite position and the ray path calculation. The position of the Envisat satellite is also well known thus the effect of this uncertainty is rather small, of the order of $30 \mathrm{~m}$ (Bertaux et al., 2010). The ray path calculation is done using the ECMWF neutral density analysis data and it causes at maximum $15 \mathrm{~m}$ error in the tangent altitude for ray paths at $10 \mathrm{~km}$ altitude. Above $10 \mathrm{~km}$ the effect is smaller: less than $<5 \mathrm{~m}$ for rays above $20 \mathrm{~km}$ (Sofieva et al., 2006).
In conclusion, the uncertainty in the GOMOS measurement ray path cause only negligible uncertainty to atmospheric profiles. This is also confirmed by several validation studies where no altitude shift has been found (see e.g., Meijer et al., 2004; Bertaux et al., 2010).

\section{Vertical resolution}

Due to the stellar occultation measurement principle and measurement geometry, the vertical resolution of GOMOS is very good. The sampling resolution of GOMOS is between $0.5-1.7 \mathrm{~km}$. When the occultation takes place in the orbital plane, the sampling resolution is the lowest $(1.7 \mathrm{~km})$ and when the occultation is more on side, the sampling resolution is better. Due to the refraction, the sampling resolution is better below $40 \mathrm{~km}$ and reaches its maximum at the lowest altitudes.

The resolution of retrieved profiles is a combination of the measurement itself and the retrieval technique. A commonly used way of analysing the resolution of the retrieved profile (and the correlations between the densities of successive layers) is to plot the so called averaging kernels. Averaging kernels are defined as the dependence on the retrieved profile $\widehat{\rho}$ on the true profile $\rho$ (see e.g. Rodgers, 2000)

$A=\frac{\partial \widehat{\rho}}{\partial \rho}$.

A typically used measure for the resolution is so called Backus-Gilbert spread (e.g., Rodgers, 2000), which is defined as the spread of the averaging kernels around the level $z_{0}$

$s\left(z_{0}\right)=12 \frac{\int A^{2}(z)\left(z-z_{0}\right)^{2} d z}{\left(\int A(z) d z\right)^{2}}$.

In GOMOS vertical inversion, Tikhonov type of smoothing is applied (Tamminen et al., 2004; Sofieva et al., 2004; Kyrölä et al., 2010). Since the sampling resolution changes from occultation to occultation, it was decided that instead of finding the optimal amount of smoothing to each occultation separately, the amount of smoothing is defined so that the retrieved profiles have the same resolution. This choice makes it easier for the end users to use GOMOS profiles since there is no need to use different averaging kernels for each occultation to interpret the measurements. In addition, more smoothing is automatically applied by this technique to oblique occultations, which is advantageous since they suffer more from scintillations. The applied target resolutions of different constituents are given in Table 2 . The choice of the target resolution for $\mathrm{O}_{3}$ was partly based on the case study of the $\mathrm{O}_{3}$ profile smoothness analysed by Sofieva et al. (2004). The impact of the GOMOS vertical inversion is demonstrated in Fig. 10 by showing the resolution of the $\mathrm{O}_{3}$ profile for three occultations with different measurement geometries. 
Table 2. Resolution of the GOMOS profile products.

\begin{tabular}{rccc}
\hline Gas & $\leq 30 \mathrm{~km}$ & $30-40 \mathrm{~km}$ & $\geq 40 \mathrm{~km}$ \\
\hline $\mathrm{O}_{3}$ & $2 \mathrm{~km}$ & $2-3 \mathrm{~km}$ & $3 \mathrm{~km}$ \\
$\mathrm{NO}_{2}, \mathrm{NO}_{3}$ & $4 \mathrm{~km}$ & $4 \mathrm{~km}$ & $4 \mathrm{~km}$ \\
aerosols & $4 \mathrm{~km}$ & $4 \mathrm{~km}$ & $4 \mathrm{~km}$ \\
\hline
\end{tabular}

In the figure the Backus-Gilbert spread is shown first without and then with applying the Tikhonov-regularization and the target resolution technique. We observe that, regardless of the sampling resolution of the occultations, the retrieved profiles have all the same resolution which is around $2 \mathrm{~km}$ at lower stratosphere and around $3 \mathrm{~km}$ in the upper stratosphere and mesosphere.

In Fig. 11, typical examples of averaging kernels for $\mathrm{O}_{3}$ and $\mathrm{NO}_{2}$ are shown. The averaging kernels are very sharp and peak clearly at the retrieval altitude (given in the figure in $\mathrm{km}$ ) showing the excellent vertical resolution of measurements. In GOMOS vertical inversion the retrieval algorithm does not depend on the noise level but only on the selected target resolution. Therefore, the averaging kernels of $\mathrm{NO}_{3}$ and aerosols are equal with the averaging kernels of $\mathrm{NO}_{2}$. The stronger smoothing applied for $\mathrm{NO}_{2}$ retrievals can be seen as the wider averaging kernels compared to $\mathrm{O}_{3}$ averaging kernels.

As typically done in retrievals of limb instruments, spherically symmetric atmosphere around the tangent point of each occultation is locally assumed also in the GOMOS retrieval. The GOMOS measurement geometry is such that the length of the ray path inside the atmospheric below $100 \mathrm{~km}$ with a $15 \mathrm{~km}$ tangent altitude is about $2100 \mathrm{~km}$. The impact of the spherical symmetry assumption depends on the atmospheric conditions and is naturally largest around poles where strong atmospheric gradients are found during polar vortex periods. When analysing ozone profiles from limb viewing instruments it is important to keep this representation issue in mind.

\section{GOMOS error estimates}

\subsection{GOMOS random error estimates of $\mathrm{O}_{3}, \mathrm{NO}_{2}, \mathrm{NO}_{3}$ and aerosols}

The main contributor in GOMOS error budget is the random measurement noise. In Fig. 12 examples of the random error estimates of $\mathrm{O}_{3}, \mathrm{NO}_{2}, \mathrm{NO}_{3}$ and aerosols are shown for representative star types. The error estimate, also known as the precision, characterises the random error component in the GOMOS retrieval (both spectral and vertical inversion) that consist of the propagation of the measurement noise (as discussed in Sect. 3) and the random modelling error caused by incorrect scintillation correction (discussed in Sect. 4.1 and
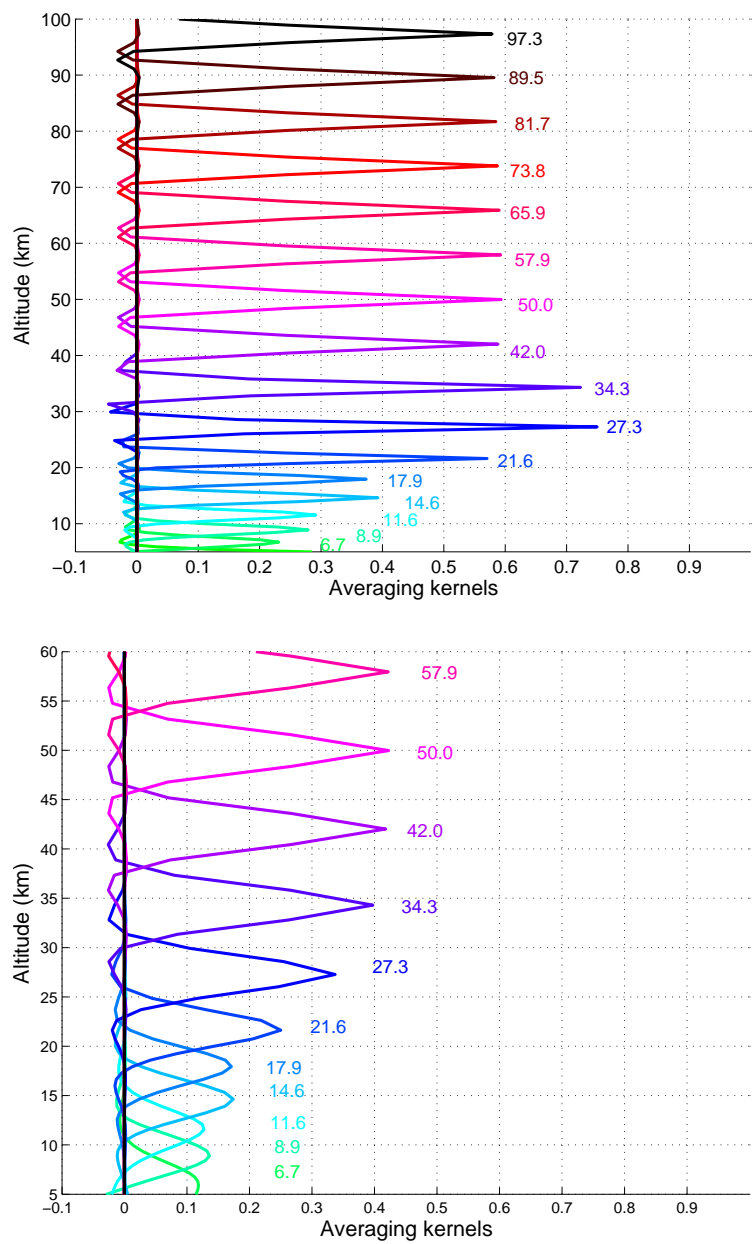

Fig. 11. Examples of averaging kernels. Top panel: $\mathrm{O}_{3}$, bottom panel: $\mathrm{NO}_{2}$. The averaging kernnels of $\mathrm{NO}_{3}$ and aerosols are equal with the averaging kernels of $\mathrm{NO}_{2}$. The averaging kernels peak at the altitude they corresond (given in the figure in $\mathrm{km}$ ). Note that only every 5 th averaging kernel is plotted.

(Sofieva et al., 2010)). For each of the constituents we show the error estimates of both oblique (dashed lines) and vertical measurement geometry (solid lines). Note, that the examples correspond to particular atmospheric conditions, so slight inconsistency with theoretical expectations can be seen in some of the curves. In general, the error estimates are smallest in the case of bright stars (column on left) and largest with dim stars (column on right).

The random error of $\mathrm{O}_{3}$ varies depending on the altitude range and the stellar type. With hot and medium temperature stars that are also of bright or medium brightness, the ozone profiles can be measured up to $100 \mathrm{~km}$ altitude with the precision of less than $8 \%$. At the $\mathrm{O}_{3}$ minimum, around $80 \mathrm{~km}$, the precision is the worst. The precision is the best around $40-60 \mathrm{~km}$ where it is typically $0.5-2 \%$. Above $40 \mathrm{~km}$ it is not recommended to use the cool stars because they suffer from low signal-to-noise ratio. Below $40 \mathrm{~km}, \mathrm{O}_{3}$ can be 

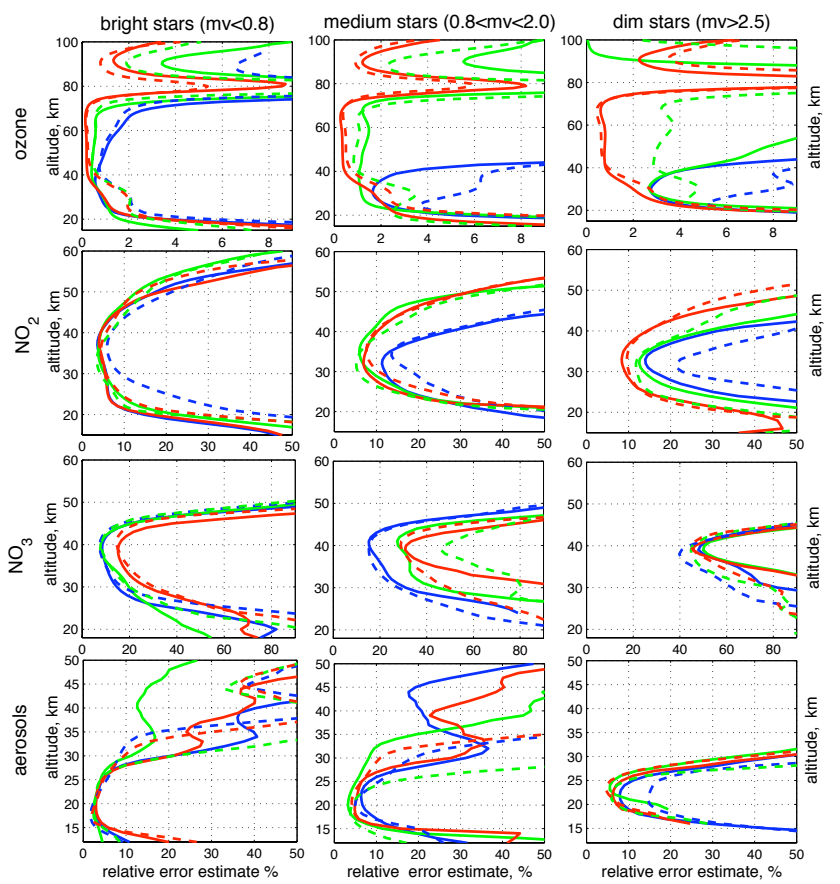

$-v$, cool $\longrightarrow v$, medium $-v$, hot ---0 , cool ---0 , medium ---0 , hot

Fig. 12. GOMOS error estimates of $\mathrm{O}_{3}$ (top row), $\mathrm{NO}_{2}$ (second row), $\mathrm{NO}_{3}$ (third row) and aerosols (bottom row) for representative cases: bright star (first column), typical star (middle column) and dim star (last column). The dashed lines correspond to oblique occultations and the solid lines to occultations in orbital plane. Stellar temperature is indicated with the line colour: hot stars (red), medium stars (green) and cool stars (blue). These values correspond to the upcoming data processing (IPF Version $6.0)$.

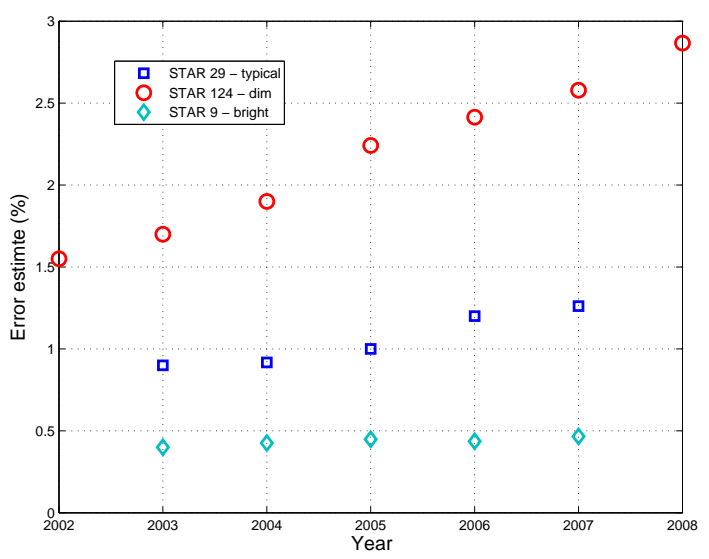

Fig. 13. Averaged error estimates for three hot stars at $50 \mathrm{~km}$ as a function of time. Circle: Star number $9\left(M_{\mathrm{V}}=0.45, T=24000 \mathrm{~K}\right)$, square: Star number $29\left(M_{\mathrm{V}}=1.7, T=10200 \mathrm{~K}\right)$, diamond: star number $124\left(M_{\mathrm{V}}=2.7, T=26000 \mathrm{~K}\right)$.

measured with also cool and dim stars. The precision between $20-40 \mathrm{~km}$ is around $1-3 \%$ and it is degrading to $10 \%$ at $15 \mathrm{~km}$. Below $15 \mathrm{~km}$, the precision degrades strongly and individual occultations do not carry much information.
The precision of the $\mathrm{NO}_{2}$ retrieval does not depend on the stellar type as strongly as the $\mathrm{O}_{3}$ retrieval. With reasonably bright stars, $\mathrm{NO}_{2}$ can be measured at $20-50 \mathrm{~km}$ altitude range with $10-20 \%$ precision. In the case of high $\mathrm{NO}_{2}$ concentration, e.g., after a strong solar proton event, $\mathrm{NO}_{2}$ can be measured up to $65 \mathrm{~km}$ altitude (not shown here) (Seppälä et al., 2004).

$\mathrm{NO}_{3}$ can be measured in the $25-45 \mathrm{~km}$ altitude range with the precision of $20-40 \%$ when bright and medium brightness stars are used. Slightly better results are obtained with the cool stars.

Aerosols can be measured from $15 \mathrm{~km}$ up to $30 \mathrm{~km}$ with about $5-10 \%$ precision. Below $15 \mathrm{~km}$, the precisions degrades to $30 \%$. The stellar temperature does not have a significant impact on the aerosol retrievals.

The impact of the scintillation is related to the occultation geometry. In Fig. 12, the error estimates for both oblique and vertical occultations are given. It can be observed that, despite that the scintillation effect is the largest in the oblique occultations, this does not show up strongly in the results. For $\mathrm{O}_{3}$ we observe slightly degraded (about $1-2 \%$ ) error estimates at $20-40 \mathrm{~km}$. In oblique occultations the vertical sampling becomes denser. When the smoothing is applied using the target resolution there is more measurements that are effectively used in the smoothing. This compensates the noisy measurements more in the oblique geometry. At high altitudes, e.g., around the second $\mathrm{O}_{3}$ maximum, the precision is the best in the case of oblique occultations.

The error estimates shown in Fig. 12 correspond to the error estimate values reported in the GOMOS data products together with the profile data in the upcoming IPF Version 6. In IPF Version 5 the reported error estimates include measurement noise and an (overestimated) ad-hoc estimate for the scintillation contribution.

\subsection{Instrument aging}

The amount of dark charge on the GOMOS CCD detectors has increased due to aging. This affects directly the signalto-noise ratio of the measurements and can be seen as a gradual decrease in the data quality. By analysing the data quality of occultations close to equator where the changes in the gas concentrations are small, we can see how the aging affects the error estimates. In Fig. 13, the yearly changes (median over each year) of the $\mathrm{O}_{3}$ error estimates at $50 \mathrm{~km}$ are seen. The altitude region was selected to be above the altitude range affected by scintillations and the occultations were selected to be close to the equator. The aging seems to have the largest effect on stars with weaker signal-to-noise ratio (star 124). In the examples shown in Fig. 13 we see that the error estimates get almost twice as large, from $1.5 \%$ to $3 \%$ in 7 years $(2002-2008)$ whereas the change for stars with a higher signal-to-noise ratio (stars 9 and 29) is small, less than $0.5 \%$ in 5 years (2003-2007). These results were 
Table 3. GOMOS data characteristics and error contributions due to systematic and random errors. The values correspond to the night-time measurements. For $\mathrm{NO}_{2}$ the higher altitude limit corresponds to case with high $\mathrm{NO}_{2}$ concentration. $(*)$ The impact of the systematic errors due to the uncertainty in cross sections for $\mathrm{NO}_{2}$ and $\mathrm{NO}_{3}$ is only rough estimate.

\begin{tabular}{|c|c|c|c|c|}
\hline $\begin{array}{r}\text { Data } \\
\text { characteristics }\end{array}$ & $\mathrm{O}_{3}$ & $\mathrm{NO}_{2}$ & $\mathrm{NO}_{3}$ & $\begin{array}{r}\text { Aerosol } \\
\text { extinction }\end{array}$ \\
\hline $\begin{array}{r}\text { Altitude range } \\
\text { range }\end{array}$ & $15-100 \mathrm{~km}$ & $20-50(65) \mathrm{km}$ & $25-50 \mathrm{~km}$ & $10-40 \mathrm{~km}$ \\
\hline Resolution & $\begin{array}{l}2 \mathrm{~km} \text { stratosphere } \\
3 \mathrm{~km} \text { mesosphere }\end{array}$ & $4 \mathrm{~km}$ & $4 \mathrm{~km}$ & $4 \mathrm{~km}$ \\
\hline $\begin{array}{l}\text { Random errors: } \\
\text { Measurement noise } \\
\text { and scintillations }\end{array}$ & $\begin{array}{l}10 \% \text { around } 15 \mathrm{~km} \\
0.5-4 \% \text { stratosphere } \\
2-10 \% \text { mesosphere }\end{array}$ & $\begin{array}{r}10-20 \% \\
\text { slightly increas }\end{array}$ & $\begin{array}{l}20-40 \% \\
\text { g with time }\end{array}$ & $\begin{array}{r}30 \% \text { around } 10 \mathrm{~km} \\
2-10 \% \text { at } 15-25 \mathrm{~km} \\
10-50 \% 25-40 \mathrm{~km}\end{array}$ \\
\hline $\begin{array}{r}\text { Systematic errors: } \\
\text { Aerosol } \\
\text { model selection }\end{array}$ & $\begin{array}{l}\sim 20 \% \text { below } 20 \mathrm{~km} \\
1-5 \% \text { at } 20-25 \mathrm{~km} \\
<1 \% \text { above } 25 \mathrm{~km}\end{array}$ & $\begin{array}{r}\sim 10 \% \text { at } 15-20 \mathrm{~km} \\
0-5 \% \text { at } 20-25 \mathrm{~km} \\
\text { negligible elsewhere }\end{array}$ & $\begin{array}{r}\text { negligible } \\
\text { above } 25 \mathrm{~km}\end{array}$ & $\begin{array}{r}<10 \% \text { below } 35 \mathrm{~km} \\
10-50 \% \\
\text { at } 35-40 \mathrm{~km}\end{array}$ \\
\hline $\begin{array}{r}\text { Temperature } \\
\text { uncertainty }\end{array}$ & $\begin{array}{l}<0.5 \% \text { at } 30-60 \mathrm{~km} \\
\text { negligible elsewhere }\end{array}$ & negligible & negligible & - \\
\hline $\begin{array}{l}\text { Uncertainty in } \\
\text { cross sections }\end{array}$ & $\sim 1 \%$ & few per-cents $(*)$ & few per-cents $(*)$ & - \\
\hline $\begin{array}{l}\text { Uncertainty in } \\
\text { neutral density }\end{array}$ & $\begin{array}{r}<1 \% \text { below } 20 \mathrm{~km} \\
\text { negligible elsewhere }\end{array}$ & negligible & negligible & $\begin{array}{r}<5 \% \text { below } 22 \mathrm{~km} \\
5-15 \% \text { at } 22-40 \mathrm{~km}\end{array}$ \\
\hline
\end{tabular}

obtained using the GOMOS processor IPF Version 5 but similar values are expected in Version 6.

\subsection{Comparing error estimates with geographical validation}

Several validation studies based on comparing ground based and balloon borne instruments with GOMOS $\mathrm{O}_{3}$ profiles show bias of less than $\pm 2 \%$ between $20-40 \mathrm{~km}$ in tropics and middle latitudes (Meijer et al., 2004; van Gijsel et al., 2010). This is in good agreement with the results presented here indicating that the random error is dominating the GOMOS error budget. Also, the validation studies show that the bias is independent on stellar characteristics, temperature and magnitude even though in individual profiles the precision depends strongly on the star (Meijer et al., 2004; van Gijsel et al., 2010). Also, a slightly larger negative bias (5-10\%) is observed at high latitudes (Meijer et al., 2004; Tamminen et al., 2006; van Gijsel et al., 2010). That could possible be related to the illumiation condition of the measurements at high latitudes in the North, but more work is needed to understand properly the reason for this. The estimated precision of the GOMOS measurements is at low altitudes (close to tropopause) about $10 \%$ and systematic error $20 \%$ (due to the uncertainty in aerosols). Validation studies show also systematic positive bias of (10-30\%) close to tropopause Meijer et al. (2004); Mze et al. (2010); van Gijsel et al. (2010), which might be related to the uncertainty in the aerosol model selection. For a recent review of GOMOS validation results, see Bertaux et al. (2010).

The validation of $\mathrm{NO}_{2}$ and $\mathrm{NO}_{3}$ profiles is challenging due to the large diurnal variability in their concentration and limited number of reference measurements. In Verronen et al. (2009) 5-15\% agreement with Envisat/MIPAS instrument and GOMOS was found in the stratosphere. Validation of GOMOS $\mathrm{NO}_{2}$ and $\mathrm{NO}_{3}$ with limited number of balloon borne measurements was performed in Renard et al. (2008) where no systematic bias in the profiles was found. Also, preliminary comparisons with GOMOS and SAGE III lunar occultations of $\mathrm{NO}_{3}$ does not show any significant systematic bias (personal communication with Janne Hakkarainen).

\section{Summary}

The stellar occultation instrument GOMOS, on-board the Envisat satellite, was launched in 2002. Since then, it has provided global measurements of $\mathrm{O}_{3}, \mathrm{NO}_{2}, \mathrm{NO}_{3}$ and aerosol profiles with high vertical resolution. We have here discussed the data characterisation and error estimation of $\mathrm{O}_{3}$, $\mathrm{NO}_{2}, \mathrm{NO}_{3}$ and aerosol profiles of GOMOS night-time occultations. 
The GOMOS data characteristics together with the random and the systematic errors are summarized in Table 3. The main sources of the GOMOS errors are due to random effects: measurement noise and scintillations. The largest part of the systematic error is due to imperfect aerosol modelling, which impacts mainly the $\mathrm{O}_{3}$ and aerosol retrievals. The valid altitude range for the $\mathrm{O}_{3}$ measurements is roughly $15-100 \mathrm{~km}$ with the exception that cool and weak stars can provide accurate ozone measurements only in the stratosphere. For $\mathrm{NO}_{2}$ the valid altitude range is $20-50 \mathrm{~km}$ with the exception that when there is a high $\mathrm{NO}_{2}$ load in the upper atmosphere, e.g., due to solar proton event or an intensive $\mathrm{NO}_{\mathrm{x}}$ descent from the thermosphere, the valid altitude range extends up to $65 \mathrm{~km}$. $\mathrm{NO}_{3}$ can be measured at $25-45 \mathrm{~km}$ and aerosols at $10-40 \mathrm{~km}$. The GOMOS products also provide data at the other altitudes, outside the range considered to be valid. The error estimates that are reported together with the GOMOS profiles do not include the systematic errors.

GOMOS Level $1 \mathrm{~b}$ and Level 2 data are available via ESA website (http://eopi.esa.int/esa/esa?cmd=submission\ \&aoname $=$ cat 1 ) and registration is required. Instructions how to register and get GOMOS off-line data and GOMOS near real time data can be found at http:// envisat.esa.int/handbooks/gomos/CNTR3.htm. A comprehensive documentation for the GOMOS instrument including the data disclaimer can be found at http://envisat.esa. int/handbooks/gomos/. The GOMOS Algorithm Theoretical Basis Document (ATBD) can be found at http://envisat.esa. int/instruments/gomos/atbd/.

Acknowledgements. We thank the anonymous reviewers for their useful comments. This work has been partly supported by ESA GOMOS Quality Working Group, Finnish Academy's project MIDAT and Viktoria Sofieva's and Marko Laine's Academy Post.Doc projects.

Edited by: P. Bernath

\section{References}

Bertaux, J. L., Hauchecorne, A., Dalaudier, F., Cot, C., Kyrölä, E., Fussen, D., Tamminen, J., Leppelmeier, G. W., Sofieva, V., Hassinen, S., d'Andon, O. F., Barrot, G., Mangin, A., Théodore, B., Guirlet, M., Korablev, O., Snoeij, P., Koopman, R., and Fraisse, R.: First results on GOMOS/Envisat, Adv. Space Res., 33, 10291035, 2004.

Bertaux, J. L., Kyrölä, E., Fussen, D., Hauchecorne, A., Dalaudier, F., Sofieva, V., Tamminen, J., Vanhellemont, F., Fanton D’Andon, O., Barrot, G., Mangin, A., Blanot, L., Lebrun, J. C., Pérot, K., Fehr, T., Saavedra, L., and Fraisse, R.: Global ozone monitoring by occultation of stars: an overview of GOMOS measurements on ENVISAT, Atmos. Chem. Phys. Discuss., 10, 9917-10076, doi:10.5194/acpd-10-9917-2010, 2010.

Burrows, J. P., Richter, A., Dehn, A., Deters, B., s. Himmelmann, Voigt, S., and Orphal, J.: Atmospheric remote-sensing reference data from GOME - 2. temperature-dependent absorption cross sections of $\mathrm{O}_{3}$ in the 231-794 $\mathrm{nm}$ range, J. Quant. Spectrosc. Radiat. Transfer, 61, 509-517, 1999.

Dalaudier, F., Kan, V., and Gurvich, A. S.: Chromatic refraction with global ozone monitoring by occultation of stars. I. Description and scintillation correction, Appl. Optics, 40, 866-877, 2001.

Fussen, D., Vanhellemont, F., Bingen, C., Kyrölä, E., Tamminen, J., Sofieva, V., Hassinen, S., Seppälä, A., Verronen, P., Bertaux, J.-L., Hauchecorne, A., Dalaudier, F., Renard, J.-B., Fraisse, R., Fanton d'Andon, O., Barrot, G., Mangin, A., Théodore, B., Guirlet, M., Koopman, R., Snoeij, P., and Saavedra, L.: Global measurement of the mesospheric sodium layer by the star occultation instrument GOMOS, Geophys. Res. Lett., 31, L24110, doi: 10.1029/2004GL021618, 2004.

Hauchecorne, A., Bertaux, J.-L., Dalaudier, F., Russell, J. M., Mlynczak, M. G., Kyrölä, E., and Fussen, D.: Large increase of $\mathrm{NO}_{2}$ in the north polar mesosphere in January-February 2004: Evidence of a dynamical origin from GOMOS/ENVISAT and SABER/TIMED data, Geophys. Res. Lett., 34, 3810, doi: 10.1029/2006GL027628, 2007.

Hays, R. G. and Roble, P. B.: Stellar spectra and atmospheric composition, J. Atmos. Sci., 25, 1141-1153, 1968.

Kyrölä, E. and Tamminen, J.: GOMOS mission planning, in: ESAMS99, European Symposium on Atmospheric Measurements from Space, vol. WPP-161, 101-110, ESA, Noordwijk, 1999.

Kyrölä, E., Tamminen, J., Leppelmeier, G. W., Sofieva, V., Hassinen, S., Bertaux, J.-L., Hauchecorne, A., Dalaudier, F., Cot, C., Korablev, O., d'Andon, O. F., Barrot, G., Mangin, A., Theodore, B., Guirlet, M., Etanchaud, F., Snoeij, P., Koopman, R., Saavedra, L., Fraisse, R., Fussen, D., and Vanhellemont, F.: GOMOS on Envisat: An overview, Adv. Space Res., 33, 1020-1028, 2004.

Kyrölä, E., Tamminen, J., Sofieva, V., Bertaux, J. L., Hauchecorne, A., Dalaudier, F., Fussen, D., Vanhellemont, F., Fanton d'Andon, O., Barrot, G., Guirlet, M., Mangin, A., Blanot, L., Fehr, T., Saavedra de Miguel, L., and Fraisse, R.: Retrieval of atmospheric parameters from GOMOS data, Atmos. Chem. Phys. Discuss., 10, 10145-10217, doi:10.5194/acpd-10-10145-2010, 2010.

Laine, M. and Tamminen, J.: Aerosol model selection and uncertainty modelling by adaptive MCMC technique, Atmos. Chem. Phys., 8, 7697-7707, doi:10.5194/acpd-8-7697-2008, 2008.

Meijer, Y. J., Swart, D. P. J., Allaart, M., Andersen, S. B., Bodeker, G., Boyd, Braathena, G., Calisesia, Y., Claude, H., Dorokhov, V., von der Gathen, P., Gil, M., Godin-Beekmann, S., Goutail, F., Hansen, G., Karpetchko, A., Keckhut, P., Kelder, H. M., Koelemeijer, R., Kois, B., Koopman, R. M., Lambert, J.-C., Leblanc, T., McDermid, I. S., Pal, S., Kopp, G., Schets, H., Stubi, R., Suortti, T., Visconti, G., , and Yela, M.: Pole-to-pole validation of ENVISAT/GOMOS ozone profiles using data from groundbased and balloon-sonde measurements, J. Geophys. Res., 109, D23305, doi:10.1029/2004JD004834, 2004.

Mze, N., Hauchecorne, A., Bencherif, H., Dalaudier, F., and Bertaux, J.-L.: Climatology and comparison of ozone from ENVISAT/GOMOS and SHADOZ/balloon-sonde observations in the southern tropics, Atmos. Chem. Phys., 10, 8025-8035, doi: 10.5194/acp-10-8025-2010, 2010.

Press, W. H., Teukolsky, S. A., Vetterling, W. T., and Flannery, B. P.: Numerical Recipes in FORTRAN, The Art of Scientific Comput- 
ing, Clarendon Press, Oxford, 1992.

Renard, J., Berthet, G., Brogniez, C., Catoire, V., Fussen, D., Goutail, F., Oelhaf, H., Pommereau, J., Roscoe, H. K., Wetzel, G., Chartier, M., Robert, C., Balois, J., Verwaerde, C., Auriol, F., François, P., Gaubicher, B., and Wursteisen, P.: Validation of GOMOS-Envisat vertical profiles of $\mathrm{O}_{3}, \mathrm{NO}_{2}, \mathrm{NO}_{3}$, and aerosol extinction using balloon-borne instruments and analysis of the retrievals, J. Geophys. Res. (Space Physics), 113, A02302, doi: 10.1029/2007JA012345, 2008.

Rodgers, C. D.: Inverse Methods for Atmospheric sounding: Theory and Practice, World Scientific, Singapore, 2000.

Seppälä, A., Verronen, P. T., Kyrölä, E., Hassinen, S., Backman, L., Hauchecorne, A., Bertaux, J. L., and Fussen, D.: Solar Proton Events of October-November 2003: Ozone depletion in the Northern hemisphere polar winter as seen by GOMOS/Envisat, Geophys. Res. Lett., 31, L19107, doi:10.1029/2004GL021042, 2004.

Seppälä, A., Verronen, P. T., Clilverd, M. A., Randall, C. E., Tamminen, J., Sofieva, V. F., Backman, L., and Kyrölä, E.: Arctic and Antarctic polar winter $\mathrm{NO}_{x}$ and energetic particle precipitation in 2002-2006, Geophys. Res. Lett., 34, L12810, doi: 10.1029/2007GL029733, 2007.

Sofieva, V., Tamminen, J., and Kyrölä, E.: Modeling errors of GOMOS measurements: A sensitivity study, in: Atmosphere and Climate, Studies by Occultation Methods, edited by: Foelsche, U., Kirchengast, G., and Steiner, A., 67-78, Springer, 2006.

Sofieva, V. F., Tamminen, J., Haario, H., Kyrölä, E., and Lehtinen, M.: Ozone profile smoothness as a priori information in the inversion of limb measurements, Ann. Geophys., 22, 3411-3420, doi:10.5194/angeo-22-3411-2004, 2004.

Sofieva, V. F., Kan, V., Dalaudier, F., Kyrölä, E., Tamminen, J., Bertaux, J., Hauchecorne, A., Fussen, D., and Vanhellemont, F.: Influence of scintillation on quality of ozone monitoring by GOMOS, Atmos. Chem. Phys., 9, 9197-9207, doi:10.5194/acp-99197-2009, 2009.

Sofieva, V. F., Vira, J., Kyrölä, E., Tamminen, J., Kan, V., Dalaudier, F., Hauchecorne, A., Bertaux, J., Fussen, D., Vanhellemont, F., Barrot, G., and Fanton D'Andon, O.: Retrievals from GOMOS stellar occultation measurements using characterization of modeling errors, Atmos. Meas. Tech., 3, 1019-1027, doi: 10.5194/amt-3-1019-2010, 2010.

Tamminen, J.: Validation of nonlinear inverse algorithms with Markov chain Monte Carlo method, J. Geophys. Res., 109, D19303, doi:10.1029/2004JD004927, 2004.
Tamminen, J. and Kyrölä, E.: Bayesian solution for nonlinear and non-Gaussian inverse problems by Markov chain Monte Carlo method, J. Geophys. Res., 106, 14377-14390, 2001.

Tamminen, J., Kyrölä, E., and Sofieva, V.: Does prior information improve measurements?, in: Occultations for Probing Atmosphere and Climate - Science from the OPAC-1 Workshop, edited by: Kirchengast, G., Foelsche, U., and Steiner, A., Springer Verlag, 87-98, 2004.

Tamminen, J., Karhu, J., Kyrölä, E., Hassinen, S., Kyrö, E., Karpechko, A., and Piacentini, E.: GOMOS ozone profiles at high latitudes: comparison with Marambio and Sodankylä sonde measurements, in: Atmosphere and Climate, Studies by Occultation Methods, edited by: Foelsche, U., Kirchengast, G., and Steiner, A., Springer, 47-54, 2006.

van Gijsel, J. A. E., Swart, D. P. J., Baray, J., Bencherif, H., Claude, H., Fehr, T., Godin-Beekmann, S., Hansen, G. H., Keckhut, P., Leblanc, T., McDermid, I. S., Meijer, Y. J., Nakane, H., Quel, E. J., Stebel, K., Steinbrecht, W., Strawbridge, K. B., Tatarov, B. I., and Wolfram, E. A.: GOMOS ozone profile validation using ground-based and balloon sonde measurements, Atmos. Chem. Phys. Discuss., 10, 8515-8551, doi:10.5194/ acpd-10-8515-2010, 2010.

Verronen, P. T., Seppälä, A., Clilverd, M. A., Rodger, C. J., Kyrölä, E., Enell, C.-F., Ulich, T., and Turunen, E.: Diurnal variation of ozone depletion during the October-November 2003 solar proton events, J. Geophys. Res., 110, A09S32, doi: 10.1029/2004JA010932, 2005.

Verronen, P. T., Ceccherini, S., Cortesi, U., Kyrölä, E., and Tamminen, J.: Statistical comparison of night-time $\mathrm{NO}_{2}$ observations in 2003-2006 from GOMOS and MIPAS instruments, Adv. Space Res., 43, 1918-1925, doi:10.1016/j.asr.2009.01.027, 2009.

Vervack, R. J., Yee, J., DeMajistre, R., and Swartz, W. H.: Intercomparison of MSX/UVISI-derived ozone and temperature profiles with ground-based, SAGE II, HALOE, and POAM III data, J. Geophys. Res., 108, ACH 2-1, 2003.

Yee, J.-H., Jr., R. J. V., Demajistre, R., Morgan, F., Carbary, J. F., Romick, G. J., Morrison, D., Lloyd, S. A., DeCola, P. L., Paxton, L. J., Anderson, D. E., Kumar, C. K., and Meng, C.I.: Atmospheric remote sensing using a combined extinctive and refractive stellar occultation technique, 1. overview and proof-of-concept observations, J. Geophys. Res., 107(10), 1029, doi:10.1029/2001JD000794, 2002. 